\title{
A PRIMEIRA FIGURA DE EXCEÇÃO: O GÊNIO NO PENSAMENTO NIETZSCHIANO
}

\author{
THE FIRST FIGURE OF EXCEPTION: GENIUS IN THOUGHT NIETZSCHIAN
}

Eduardo Marcos Silva de Oliveira*

\section{RESUMO}

O presente artigo ocupa-se com a apresentação do pensamento do jovem Nietzsche, descrevendo o gênio na arte trágica na perspectiva de $O$ nascimento da tragédia, tendo-a como primeira experimentação filosófica de Nietzsche. Dessa forma, optamos por desenvolver este artigo enfatizando a definição de uma das figuras de exceção em sua produção filosófica, o gênio. Expressão que sintetiza a primeira busca por uma nova concepção de valores em sua filosofia. Analisando esse primeiro período de produção do filósofo, o texto se desenvolve sobre a constatação feita pelo autor de gênio apolíneo e gênio dionisíaco, e como essa definição é descrita na formação da cultura ocidental e é realçada na sociedade moderna.

PALAVRAS-CHAVE: Nietzsche. Gênio. Apolíneo. Dionisíaco. Arte.

\section{ABSTRACT}

This article deals with the presentation of the thought of the young Nietzsche, describing the genius in tragic art from the perspective of The birth of tragedy, taking it as first philosophical experimentation Nietzsche. In this way, we chose to develop this article emphasizing the definition of the exception of figures in his philosophical production, genius. Expression that sums up the first search for a new concept of values in his philosophy. Analyzing this first philosopher production period, text develops on the finding made by the author of apollinian genius and dionysian genius, and how this definition is described in the formation of western culture and it is enhanced in modern society.

KEYWORDS: Nietzsche. Genius. Apollinian. Dionysian. Art.

\footnotetext{
* Mestre em Ciências da Religião pela PUC-Minas, Professor de Filosofia da Escola Superior Dom Helder Câmara. e-mail: edumasilo@gmail.com
} 


\section{INTRODUÇÃO}

A busca pela autossuperação do homem vem acompanhando o desenvolvimento da humanidade ao longo de sua história. Segundo o referencial teórico deste estudo, frente aos conceitos da formação do mundo ocidental, o homem encontra-se moldado por uma moralidade socrático-cristã voltada para o princípio da conservação ${ }^{1}$.

Tendo esta concepção avivada no seio da sociedade moderna, já em seus primeiros escritos, Nietzsche diagnostica a preponderância de uma filosofia de matriz apolínea frente à formação cultural de sua sociedade e, concomitantemente, o "esquecimento" ou enfraquecimento do princípio dionisíaco do homem, manifestado, de acordo com nosso autor, pelo gênio. Segundo nossa leitura, o conceito de gênio apresenta-se em diversos momentos da filosofia de Nietzsche, como mostram os fragmentos póstumos de 1886 e de obras posteriores

\section{a Zaratustra.}

Para realizarmos essa separação cronológica dos escritos do filósofo, utilizaremos a metodologia dos comentadores citados nesta pesquisa de separar os momentos da vida de Nietzsche em três etapas ${ }^{2}$ distintas: a) o jovem Nietzsche; b) o período intermediário; e c) o Nietzsche maduro ou adulto. Tal formulação será determinante para didaticamente compreendermos o processo estruturante da filosofia nietzschiana. Dessa forma, apontaremos o gérmen de sua proposta de um tipo que se destaca em relação ao homem comum ainda no início de suas obras.

Procuraremos abordar a questão da arte trágica, segundo a interpretação de Nietzsche, como possibilidade de afirmação da vida e a manifestação dos impulsos artísticos como forma originária de criação.

\section{O GÊNIO EM O NASCIMENTO DA TRAGÉDIA}

A estrutura da filosofia de Nietzsche em razão de um tipo ${ }^{3}$ afirmador da vida em sua mais alta abundância pode ser dividida em três momentos distintos, sendo eles: a) O gênio,

\footnotetext{
${ }^{1} \mathrm{O}$ trabalho apresentado é parte da dissertação intitulada Übermensch nietzschiano e o cristianismo: Estudos sobre a filosofia da religião em Nietzsche, sobre orientação do professor Dr. Flávio Augusto Senra Ribeiro.

2 É evidenciada uma divergência entre pesquisadores de Nietzsche sobre a cronologia de sua elaboração filosófica. Contudo, em um contexto geral, fica caracterizado que a divisão da vida e obra do filósofo em três distintos períodos é a melhor forma de compreender a elaboração de sua produção.

3 Segundo Silva (2008), fatores de suma importância nas obras de Nietzsche é sua compreensão sobre personagens históricos e literários para exemplificar suas ideias. Dessa forma, sua problematização avança sobre as formas de valoração e seus tipos são apresentados como forma de exemplificação. Com esse método,
} 
abordado na primeira fase do filósofo, b) o espírito livre descrito no período intermediário e c) o além-do-homem apresentado na terceira e última fase de sua filosofia. Como não é possível, num artigo, abordar todo o sistema filosófico do nosso autor, por este motivo, ocupar-nosemos em discorrer somente sobre a primeira etapa de seu pensamento, distinguida pela abordagem do gênio na divisão/dualidade de "apolíneo e dionisíaco"4, realizando uma análise da tragédia grega, que corresponde à produção de sua obra primogênita, $O$ nascimento da tragédia no espírito da música (1872). Rohde (1845-1898), em sua resenha publicada no Norddeutsche Allgemeine Zeitung, afirma que o ponto característico dessa obra pode ser compreendido como um rebelar-se encorajador do jovem Nietzsche influenciado pela música de Richard Wagner (1813-1883) e pela filosofia de Schopenhauer (1788-1860).

No ano de 1873 Nietzsche escreve A filosofia na idade trágica dos gregos e Sobre a verdade e a mentira em sentido extramoral, porém esses escritos somente foram publicados postumamente. Posteriormente, o autor produziu Considerações extemporâneas, ou Considerações intempestivas (1873-76), sendo essa obra o conjunto de quatro artigos que criticavam a cultura alemã perante o período modernista. Nelas, Nietzsche manifesta sua crítica ao domínio da razão sobre a vontade humana, determinado, inicialmente, pelo socratismo e, em seguida, pelo cristianismo. Sobre esse domínio cultural e artístico da história diz Jaeger (2003, p. 26):

A marcha da história da formação torna-se visível, antes de tudo, pela consideração do conjunto do flutuante desenvolvimento histórico da vida e do esforço artístico para eternizar as normas ideais em que o gênio criador de cada época encontra a sua expressão mais alta.

Igualmente, dentre o conjunto das primeiras ${ }^{5}$ obras do autor, $O$ nascimento da tragédia apresenta pontos culminantes em sua estrutura que delineiam o pensamento do jovem Nietzsche. Ela é alicerçada em uma explanação sobre a origem e o intuito da arte trágica,

\footnotetext{
Nietzsche descreve através de sua tipologia uma abrangente compreensão do homem. Esse apontamento figura tanto no campo filosófico, quanto cultural, psicológico e moral. No desenvolver de sua filosofia, Nietzsche busca exemplificar novos tipos como princípio valorativo que representam diferentes naturezas humanas, sempre possíveis de transformação.

${ }^{4}$ As definições da cultura grega [apolíneo e dionisíaco] são descritas na filosofia nietzschiana, principalmente na primeira fase do filósofo, como os dois modos de expressão da arte. Para Nietzsche, a arte e a vida se relacionam na medida em que a primeira é a manifestação da segunda.

${ }^{5}$ Importante ressaltar que, dentre os primeiros escritos de Nietzsche, sua crítica à religião cristã ainda não se encontrava como alvo principal de sua filosofia, mas sim à arte e a moral. Entretanto, seu pensamento embasado em uma crítica à modernidade é sua estrutura sociocultural, tendo como princípio o socratismo, e acompanhará sua filosofia em todos os três períodos discriminados. Segundo Lima (2006, p. 176), durante os primeiros escritos de Nietzsche foi guardado um silêncio hostil sobre o cristianismo por parte do filósofo.
} 
baseada na "justa medida" e na uniformidade grega apontadas pelo princípio figurativo apolíneo e pela desmesura e embriaguez musical dionisíaca. Assim, remetem ao homem o princípio natural de criação e destruição, que o filósofo define como a manifestação da arte do gênio (o uno-primordial) ${ }^{6}$. Dessa forma, percebemos que o gênio entendido por Nietzsche (o dionisíaco) é contrário ao gênio compreendido por Schopenhauer (2005) de entendimento trágico do mundo, no qual o artista teria como única saída resignar-se perante a vontade, prevalecendo uma concepção (apolínea) da arte ligando ética a estética.

Segundo Nietzsche (2008b, p. 24),

[...] Apolo e Dioniso vinculam-se à nossa cognição de que no mundo helênico existe uma enorme contraposição, quanto a origens e objetivos, entre a arte do figurador plástico [Bildiner], a apolínea, e a arte não figurada [unbildlichen] da música, a de Dioniso: ambos os impulsos, tão diversos, caminham lado a lado, na maioria das vezes em discórdia aberta e incitando-se mutuamente a produções sempre novas, para perpetuar nelas a luta daquela contraposição sobre a qual a palavra comum "arte" lançava apenas aparentemente a ponte; até que, por fim, através de um miraculoso ato metafísico da "vontade" helênica, apareceram emparelhados um com o outro, e nesse emparelhamento tanto a obra de arte dionisíaca quanto a apolínea geram a tragédia [...].

Entretanto, diferentemente do pensamento de Schopenhauer (2011), no qual a arte é compreendida a partir não do artista, mas do interceptador que traz em si o vislumbre e o encantamento pelo imaginário através da razão, contrapondo-se à realidade, o apontamento nietzschiano ressalva que o gênio representa a natureza intrínseca ao homem, o irracional que ultrapassa as barreiras interpostas pela sociedade, não permitindo prender-se a conceito algum, mas consentindo a fluidez da vida. De acordo com Detienne (1988, p. 14), "Dioniso é por excelência o deus que vem; aparece, manifesta-se, faz-se reconhecer. Epifânico itinerante, Dioniso organiza o espaço em função de sua atividade ambulatória. É encontrado por toda parte, e em lugar nenhum”.

Um segundo momento importante da obra é distinguido pelo apontamento realizado por Nietzsche sobre a dissolução da arte trágica. Para o filósofo, a arte grega perdeu seu significado e começou a perecer no momento em que a racionalidade do homem teórico passou a imperar sobre a sensibilidade do artista, a manifestação do gênio. Nietzsche (2008b),

\footnotetext{
${ }^{6}$ Pascual (2005), em seu texto introdutório à obra $O$ nascimento da tragédia, afirma que o termo é uma expressão schopenhaueriana. Todavia, o conceito nietzschiano de uno-primordial sustenta-se numa autonomia frente ao conceito determinado por Schopenhauer. Segundo a definição de Araldi (2008, p. 90), o uno-primordial nietzschiano é responsável, devido a seu gênio dionisíaco, pelo aniquilamento do mundo da individuação e o esquecimento de si.
} 
inicialmente, atribui essa definição às considerações realizadas por Eurípides, ao racionalizar e limitar a arte trágica em uma visão contrária do seu propósito originário de engendramento.

Contrário ao processo de racionalização da arte, Nietzsche atribui ao gênio a capacidade de dar continuidade ao processo de criação do homem. Segundo Machado:

\begin{abstract}
O gênio é um talento para produzir aquilo para o qual não se pode fornecer nenhuma regra determinada; daí sua originalidade. Em segundo lugar, o gênio se opõe ao princípio de imitação. Os produtos do gênio são modelos exemplares, que não surgiram por imitação, nem servem para imitação de outros, mas para despertar a originalidade de outros gênios. Em terceiro lugar, a produção do gênio fornece a regra, mas ele próprio não sabe explicá-la. (MACHADO, 2006, p. 92).
\end{abstract}

A definição principal no pensamento nietzschiano de desestruturação do princípio de criação do gênio é o posicionamento da filosofia socrática, na qual Eurípides apresentava-se para Nietzsche como seu interlocutor.

Que Sócrates estivesse estreitamente relacionado à tendência de Eurípides foi algo que não escapou a seus contemporâneos, na Antiguidade; e a expressão mais eloquente dessa percepção feliz é aquela lenda circulante em Atenas, segundo a qual Sócrates costumava ajudar Eurípides em seu poetar. (NIETZSCHE, 2008b, p. 81).

Com essa influência socrática, caracteriza-se o aniquilamento do gênio dionisíaco devido à negação do trágico e desmedido, e da predominância moralizante do arquétipo apolíneo do belo e transcendente. Para Nietzsche, tal formulação foi decisiva para desnaturalizar e fragmentar a construção do gênio dionisíaco em virtude do conflito entre uma visão trágica e teórica da vida.

Ao conceder a primazia ao elemento apolíneo-racional, Sócrates destruiu a tensão entre este elemento e o dionisíaco-irracional, quebrando assim a própria harmonia. Com isso, o que ele fez foi moralizar, escolasticizar, intelectualizar a concepção trágica do mundo da Grécia antiga. (JAEGER, 2003, p. 496).

O terceiro e último momento distinto da primeira obra de Nietzsche é uma reflexão sobre a possibilidade de propor a compreensão da arte moderna através do pensar da tragédia grega, devido às múltiplas manifestações artísticas e culturais da época. Culturalmente, a sociedade moderna alemã encontra-se influenciada por uma filosofia que se estruturou em uma percepção da cultura e arte trágica grega contrária às aspirações socráticas para esboçar um conceito original de arte moderna. Da mesma forma, destaca Lima (2006) que as definições apontadas pelas filosofias de Kant (1724-1804) e, principalmente, de 
Schopenhauer apresentam uma genuína originalidade do idealismo germânico em relação ao qual Nietzsche se contrapõe.

Contudo, essas filosofias foram fundamentais para a conexão entre Alemanha e Grécia realizada pelo filósofo. Também o influenciaram os pensamentos de Goethe (1749-1832) e Schiller (1759-1805), que, segundo Nietzsche (2008b), possuíram relevância na contextualização e influência na arte moderna, mesmo sendo suas abordagens artísticas reflexionadas apenas ao apontamento apolíneo do período helenístico, sem caracterizarem a definição dionisíaca do mesmo período.

\section{A INTERPRETAÇÃO NIETZSCHIANA DE MANIFESTAÇÃO DO GÊNIO NA MODERNIDADE}

Artisticamente, a influência de Richard Wagner foi um marco capital para o desenvolvimento do conceito musical trágico descrito por Nietzsche, chave fundamental ao acesso encantador do helenismo na modernidade. Dessa forma, devido ao entendimento do jovem Nietzsche sobre a influência de Wagner junto à cultura alemã, o filósofo descreve o artista em uma carta a Erwin Rohde, em 9 de novembro de 1868, tal como foi conhecido, como sendo a ilustração do gênio tal como compreende Schopenhauer (NIETZSCHE, 1989).

De tal forma, embasados pelos mesmos princípios de compreensão do gênio entendido por Nietzsche, tanto a filosofia schopenhaueriana quanto a música wagneriana encontravamse inseridas, para Nietzsche, na mesma origem de genialidade da arte moderna, ou seja, no espírito alemão. Para Nietzsche, a arte moderna:

Só pode ser o renascimento do apolíneo-dionisíaco da tragédia. Mas significa também - e a esse respeito a influência das óperas de Wagner é fundamental - o renascimento de mitos germânicos, que, segundo $O$ nascimento da tragédia, conservam "o espírito alemão intato em sua esplêndida saúde, profundidade e força dionisíaca". Assim, o renascimento do espírito trágico grego vincula-se, em Nietzsche, ao renascimento do gênio alemão [...] (MACHADO, 2005, p. 12).

Contudo, o pensamento nietzschiano sobre o gênio alemão ultrapassa o termo apreciado por seus antecessores, pelo fato de Nietzsche compreender o conceito de gênio além das definições teóricas anteriormente disseminadas. Segundo Araldi (2009), "o projeto de criação do gênio marca um afastamento decisivo em relação à Schopenhauer, [...] apesar da adesão inicial". 
Em Crítica da faculdade do juízo, Kant determina o gênio como sendo um princípio normativo, natural do artista:

\begin{abstract}
Gênio é o talento (dom natural) que dá a regra à arte. Já que o próprio talento enquanto faculdade produtiva inata do artista pertence à natureza, também se poderia expressar assim: gênio é a inata disposição de ânimo (ingenium) pela qual a natureza dá a regra à arte. (KANT, 1990, p. 158).
\end{abstract}

Segundo Machado (2006), Schelling (1775-1854) compreende o gênio como sendo para a estética assim como o eu para a filosofia e que obtém acesso a essa definição inicial através do intelecto. Na definição schopenhaueriana, "a ação do gênio foi desde sempre encarada como uma inspiração e, como o próprio nome indica, como a atividade de um ser sobre-humano, distinto do indivíduo mesmo, que apenas periodicamente dele se apropria" (SCHOPENHAUER, 2011), sendo assim destituído de vontade.

Quanto ao gênio schopenhaueriano, Dias (1999, p. 99) o compreende como sendo "um ser que tem um excedente de força cognitiva, de inteligência e conhecimento intuitivo que o permite libertar da escravidão da vontade, e seus interesses e objetivos", que compreende essa vontade do mundo em uma visão mesmo compensadora, diferenciando-o do gênio dionisíaco nietzschiano. Ou seja, Schopenhauer (2001, p. 61), afirma que "a genialidade nada é senão a objetividade mais perfeita, ou seja, orientação objetiva do espírito; em oposição à subjetiva, que vai de par com a própria pessoa, isto é, a Vontade".

Contrapondo-se, Nietzsche compreende que o gênio de Schopenhauer não consegue abranger e sustentar o conceito de arte em sua totalidade, devido a sua separação e compreensão da arte como objetiva e subjetiva.

Embora descreva o gênio em $O$ nascimento da tragédia a partir de categorias schopenhauerianas, Nietzsche (1995, p. 62) compreende a ação do gênio como sendo um duelo entre a "'racionalidade' contra instinto", e não como uma implicação teorizada e/ou metafísica. O gênio em Nietzsche é caracterizado pela união dos impulsos apolíneos e dionisíacos, ou seja, é através desses impulsos que é possível ao artista manifestar sua criação. De acordo com Araldi (2004, p. 160), o "gênio não é aquele que sobrepuja a Vontade, ${ }^{7}$ mas aquele que a transfigura artisticamente".

\footnotetext{
${ }^{7}$ Segundo notas de Araldi (2004, p. 159-160), o gênio schopenhaueriano possui um caráter libertador do sofrimento do mundo devido a sua capacidade inata de vencer os apelos e interesses da vontade. Dessa forma, deve ser evidenciado que, enquanto para Schopenhauer o gênio é proveniente do intelecto, para Nietzsche é fruto proveniente da vida.
} 
Dessa forma, poder-se-ia afirmar que a proposta nietzschiana de arte não somente compreende a concepção estética, mas sim as múltiplas criações do homem. De acordo com Dias (2009, p. 78),

ao desmistificar a concepção do gênio, Nietzsche quer mostrar que não há na arte algo de miraculoso, que uma obra de arte é produto de um longo e penoso trabalho. Embora os artistas tenham interesse [...], em que se acredite em intuições súbitas e nas chamadas inspirações, na verdade, a improvisação artística se situa em um plano abaixo do pensamento estético, sério e trabalhosamente selecionado.

Assim, a compreensão nietzschiana de gênio apresenta uma inseparável relação entre racional e intuitiva, em que, através dessa dualidade apolíneo-dionisíaca, Nietzsche descreve a possibilidade de criar "uma magnificação ainda mais elevada (por meio da arte). Não mais a arte da aparência, mas a arte trágica era a forma de magnificação: nela, porém, aquela arte da aparência foi totalmente absorvida. Apolo e Dioniso se uniram” (NIETZSCHE, 2005, p. 30). Nessa absolvição do apolíneo pelo dionisíaco, Nietzsche compreende a música como a manifestação legitimadora da arte, tendo como princípio de renascimento da arte dionisíaca na modernidade o drama ${ }^{8}$ musical wagneriano, sendo este, segundo Machado (2005), a maior expressão alemã de valorização da arte grega como referência ao projeto de arte moderna.

Em $O$ nascimento da tragédia, a música é descrita como sendo fundadora da tragédia e "não apenas dá o conhecimento da vontade, como também proporciona a afirmação da vontade" (MACHADO, 2006, p. 238). Esta é uma diferenciação da teoria nietzschiana em relação à teoria schopenhaueriana, ou seja, apesar de Nietzsche partir do mesmo princípio originário de vontade como fundamentação do mundo, ele constrói uma "noção radicalmente nova de arte, de trágico e de gênio" (ARALDI, 2004, p. 160).

É justamente a "música"9 que Nietzsche concebe como sendo o esplendor do espírito alemão e renascimento da tragédia grega. Segundo Araldi (2009),

\footnotetext{
${ }^{8}$ Em seu escrito Richard Wagner em Bayreuth, Nietzsche afirma que o drama do artista é a união perfeita do mundo da visão com o mundo da audição. Na definição de Dias (2005), a concepção do gênio wagneriano é, para Nietzsche, elemento capital do drama, responsável pela recuperação da dimensão dionisíaca, ofuscado pelo socratismo e responsável pelo renascimento de uma cultura trágica.

${ }^{9}$ É importante possuir uma atenção sobre a influência schopenhaueriana no conceito musical nietzschiano, pois tal influência é ambígua. Essa afirmação fica evidenciada posteriormente aos escritos de Schopenhauer como educador, caracterizando o afastamento definitivo de Nietzsche com seu mestre, consequentemente, com Wagner e sua obra. Mas o principal motivo do rompimento de Nietzsche com Wagner foi sua conversão cristã, e com isso a transformação de sua arte. Em Ecce Homo, Nietzsche descreve que a obra wagneriana não é mais uma música oriunda do espírito germânico, mas sim uma música da decadência que não possibilita mais a vontade de criação.
} 
Nietzsche quer consumar o salto prodigioso da época trágica dos gregos para a sua época, afirmando o renascimento do gênio que outrora engendrou a tragédia grega. Desse modo, a tragédia renasceria no espírito da música alemã (do gênio de Wagner).

Para Nietzsche (2005), a música é a arte dionisíaca por excelência, e através dela se dá a afirmação do gênio e seu significado sobre o domínio estético. Sendo assim, evidencia-se que a proposta de Nietzsche não é retomar a vivência grega na modernidade dentro de um conceito teórico. Essa constatação foi apresentada pelo filósofo em 1870, em sua conferência "O drama musical grego". O pensador afirma a arte moderna fora das pretensões e princípios socráticos que, por sua vez, opera uma divisão entre "o conjunto da obra". ${ }^{10}$

Dessa forma, Nietzsche remete-se ao coro para exemplificar o resgate da arte trágica grega devido à inteiração existente entre espectador e artista nesse gênero artístico. Sendo o drama musical condição para tal manifestação, Lima (2006, p. 18) afirma:

Nietzsche concebe que a tradição musical germânica de Bach e Beethoven e a literária e estética de Goethe, Schiller e Winckelmann se uniram na música wagneriana e consubstanciaram um novo gênero artístico - o drama lírico -, que representaria nada menos do que o renascimento da tragédia grega.

Ao evidenciar a importância do valor da cultura grega para a cultura germânica, é possível perceber que é por meio da reprodução da arte trágica grega que o filósofo vê a possibilidade da Alemanha superar a influência socrática, que, para Nietzsche, é interpretada como contrária ao espírito germânico.

O espírito alemão intacto em sua esplêndida saúde, profundidade e força dionisíaca, qual um cavaleiro prostrado em sono, repousava e sonhava em um abismo inacessível: abismo que se eleva até nós a canção dionisíaca para nos dar a entender que também agora esse cavaleiro alemão ainda sonha o seu antiquíssimo mito dionisíaco em visões austeras e beatificadas. (NIETZSCHE, 2008b, p. 140).

O retorno ao clássico é o cerne do posicionamento de Nietzsche perante a modernidade e, concomitantemente, a alusão a Wagner é inevitável. Nesse período inicial de sua filosofia, Nietzsche atribui ao "gênio wagneriano"

\footnotetext{
${ }^{10} \mathrm{Em} O$ drama musical grego, Nietzsche indica que na arte moderna existe uma ruptura entre os artistas e o espectador, diferenciando-se da arte trágica grega. Segundo Dias (2005), tal diferenciação ocorre através da trajetória da musica alemã, em especial com Richard Wagner, que promove o renascimento do impulso dionisíaco na arte moderna, apontando para uma cultura trágica, em que o espectador encontra-se envolvido pela egrégora da arte trágica, e não pela teorização do socratismo estético.

${ }^{11}$ Nietzsche descreve em seu ensaio "Wagner em Bayreuth" uma afinidade de seu entendimento do mundo com o projeto estético da obra wagneriana. Nietzsche atribui à criação de Wagner uma singularidade típica de um
} 
gênio musical grego. Na afirmação de Pinheiro (2003, p. 211), "Wagner seria o fundador da nova ópera dramática e o autor de uma dramaturgia em que o coro ainda ocupava o lugar central".

Para Nietzsche, o coro é a essência da tragédia. O seu envolver abrange tanto o artista quanto o espectador na mesma sincronia. Diferentemente das demais manifestações, que por Schopenhauer foram interpretadas como objetivas, a música, para Nietzsche, é a anunciação da própria vida. Para Nietzsche, a música

[...] difere de todas as outras artes pelo fato de não ser reflexo do fenômeno ou, mais corretamente, da adequada objetividade [objektität] da vontade, porém reflexo imediato da própria vontade e, portanto, representa o metafísico para tudo o que é físico no mundo, a coisa em si mesma para todo fenômeno. [...] a música estimula a introvisão similiforme da universalidade dionisíaca e deixa então que a imagem similiforme emerja com suprema significatividade. (NIETZSCHE, 2008, p. 97-98).

Para Nietzsche, através da música o coro apresenta ao homem o significado da afirmação da vida, mesmo diante de suas moléstias, ou seja, em sua totalidade, ${ }^{12}$ o que Nietzsche denomina como uno-primordial. Dentre a tríade (dionisíaco, apolíneo e unoprimordial) apresentada pelo filósofo em $O$ nascimento da tragédia, este último seria "o verdadeiro criador a que Nietzsche se refere” (LIMA, 2006, p. 42).

Com essa definição, poder-se-ia dizer que Nietzsche, por meio do drama musical wagneriano, aspirava a essa possibilidade de criação do homem moderno devido a Wagner trazer consigo a tragicidade grega e, com ela, sua cultura. Sendo assim, Wagner, para o jovem Nietzsche, contrariava a cultura socrática da época que imperava na ópera. ${ }^{13}$ Seu pensamento em "O drama musical grego" enfatiza que, enquanto no drama é a canção popular que prevalece, não rompendo a conexão entre música e palavra, a ópera encontrava-se nas mãos dos letrados que diluíram a arte, aprisionando-a na palavra e na aparência. Desse modo, Nietzsche afirma aos seus contemporâneos que, com o ressurgimento da cultura trágica grega, ocorreria o aniquilamento do "mau hábito moderno de não 'se poder' gozar como homens inteiros: 'estando estes' como que despedaçados pelas artes absolutas e só rejubilando-se

gênio, tal como o filósofo o compreendia em razão de sua arte manifestar-se sem a interferência de elementos que pudessem interromper seu fluir.

${ }^{12}$ Esta ideia aborda o que para o filósofo seria posteriormente descrito como amor fati. Embora seja exposto por Nietzsche em seus escritos vindouros, fica evidenciado que a primeira fase de sua filosofia já possuía uma propensão ao amor fati, como descrito em Crepúsculo dos ídolos.

${ }^{13}$ Para Nietzsche, a ópera é o que se pode definir como a representante musical socrática, pelo fato de esta possuir os mesmos princípios. Segundo Dias (2005, p. 79), isso ocorre porque existem neste movimento artístico a precedência da palavra e a superioridade do leigo sobre o artista. 
como pedaços, ora como homens-ouvidos, ora como homens-olhos [...]” (NIETZSCHE, 2005, p. 51). ${ }^{14}$

Evidencia-se que Nietzsche, ao buscar respaldo no drama musical grego, ele o faz como fundamento da construção da cultura moderna. Para isso, o filósofo desvincula a cultura socrática (teórica) da cultura trágica (natural). Na definição de Dias, a cultura é assim definida por Nietzsche:

[...] a trágica pela certeza da indestrutibilidade da vida, e a socrática pelo amor ao saber. A primeira se manifesta através da música, a segunda se exprime pela palavra. Assim, qualquer cultura que assegure a preponderância da música é trágica, qualquer uma que dê à palavra prioridade é socrática. Na cultura moderna, na qual domina a palavra, o que prevalece são os ideais do homem teórico que, armado de conhecimentos poderosos, põe a vida a serviço da ciência. [...] Privilegiando o conhecimento em detrimento da arte, essa cultura socrática ou alexandrina desclassifica o dionisíaco e exige que ele se torne visível à razão, de forma que o trágico - a afirmação da existência - ceda lugar ao otimismo do saber e à febre de viver. (DIAS, 2005, p. 79).

Por fim, nessa reestruturação da cultura moderna, prevalece o que seria definido por Nietzsche como uma investida em prol da vida, na qual a tese da "metafísica de artista" que impulsiona o ponto capital de $O$ nascimento da tragédia, a dualidade entre o gênio apolíneo e o gênio dionisíaco, possibilita ao mundo, através do uno-primordial, confrontar o que em seguida seria identificado como uma vontade de nada, propensa ao niilismo. ${ }^{15}$ Segundo Nietzsche, "os únicos valores que $O$ nascimento da tragédia reconhece: o cristianismo é niilista no mais profundo sentido, enquanto no sentido dionisíaco é alcançado o limite único da afirmação" (NIETZSCHE, 1995, p. 62). A metafísica de artista constitui a tragédia como entendimento perante a arte e o gênio como "único poder afirmador da vida" (ARALDI, 2008, p. 91) frente aos paradigmas do cientificismo e, posteriormente, da religião, distinto da percepção, princípios e conceitos da cultura socrática.

\footnotetext{
${ }^{14}$ Esta afirmação de Nietzsche alude, em Assim falou Zaratustra, ao que o filósofo define como sendo os homens superiores. Giacóia Júnior, em sua videoconferência $O$ impacto de Nietzsche no século XX (2009), refere-se a esta citação diferenciando os homens superiores do além-do-homem por estes serem possuidores de virtudes inacabadas e/ou limitadas.

${ }^{15}$ É importante ressaltar que o termo niilismo não é apresentado em $O$ nascimento da tragédia. Aqui, a expressão se encontra no sentido de vontade de nada, que, no transcorrer do pensamento nietzschiano, será interpretado como niilismo negativo. O niilismo descrito por Nietzsche sobre $O$ nascimento da tragédia é um afirmativo, como definido pelo filósofo em Ecce Homo. Em nota, Araldi (2004, p. 44) aponta para a afirmação de Karl Löwith, que afirma que Nietzsche está, desde a juventude, em busca de um pensamento supremo afirmativo; o niilismo, por sua vez, também estaria pressuposto nos escritos da primeira fase do filósofo.
} 


\section{CONSIDERAÇÕES FINAIS}

A tentativa de destacar a formulação nietzschiana sobre um tipo superior ao homem apontado no início de suas obras nos remete a uma compreensão da arte trágica como princípio valorativo afirmador da vida, em que o resgate da cultura grega é fundamental para embasar a reedificação da cultura moderna frente à crise dos valores em que a sociedade alemã encontrava-se inserida pela teorização do socratismo. A estrutura da primeira fase da filosofia nietzschiana já se apresenta como uma referência que direciona a modernidade para uma possibilidade de reflexão sobre os valores até então pertinentes em sua composição, sendo esse posicionamento ponto determinante para o amadurecimento do pensamento do filósofo, mas esse tema uma proposta para pesquisas posteriores.

Nesta pesquisa percebemos, na estruturação do pensamento do filósofo iniciado em sua juventude, ainda influenciado pela filosofia schopenhaueriana, a necessidade de distinguir tipos superiores ao homem comum. Com isso, identificamos o gênio nietzschiano como precursor da procura de um tipo transvalorado que busca afirmar a vida através de seu ato de criar e o nobre como executor do princípio de superioridade frente a uma cultura inferior.

A descrição do gênio nas primeiras obras de Nietzsche trata-se, como vimos, da primeira figura de exceção que nosso autor apresenta na sua construção filosófica e que o acompanhara ao longo de sua produção. Este artigo teve como principal objetivo uma análise do primeiro período da filosofia nietzschiana apontando seus primeiros passos à construção de sua crítica à sociedade moderna.

\section{REFERÊNCIAS}

ARALDI, Clademir Luís. As criações do gênio e do além-do-homem: Nietzsche em transição. In: PASCHOAL, Antonio Edmilson; FREZZATTI JR., Wilson Antonio (Org.). 120 anos de Para a genealogia da moral. Ijuí: Unijuí, 2008.

ARALDI, Clademir Luís. As criações do gênio: ambivalências da "metafísica da arte" nietzschiana. Kriterion/Revista de Filosofia de Belo Horizonte, v. 50, n.119, jun. 2009. Disponívem em: <http://www.scielo.br/scielo.php?script=sci_arttext\&pid=S0100512X2009000100006>. Acesso em: 15 set. 2011.

ARALDI, Clademir Luís. Niilismo, criação, aniquilamento: Nietzsche e a filosofia dos extremos. Ijuí: Unijuí, 2004.

ARISTÓTELES. Poética. São Paulo: Abril, 1973. (Os Pensadores). 
DETIENNE, Marcel. Dionísio a céu aberto. Tradução Carmem Cavalcanti. Rio de Janeiro: Jorge Zahar, 1988.

DIAS, Rosa Maria. Amizade estelar: Schopenhauer, Wagner e Nietzsche. Rio de Janeiro: Imago, 2009.

DIAS, Rosa Maria. Nietzsche e a música. Ijuí: Unijuí, 2005.

DIAS, Rosa Maria. Nietzsche e a questão do gênio. In: PIMENTA NETO, Olímpio José; BARRENECHEA, Miguel Angel de (Org.). Assim falou Nietzsche. Rio de Janeiro: Sette Letras, 1999.

GIACÓIA JÚNIOR, Oswaldo. Balanço do século XX - paradigmas do século XXI: o impacto de Nietzsche no século XX. São Paulo: Espaço Cultural CPFL, 2009. 1 videodisco (50 min.): NTSC: Full Screen.

JAEGER, Werner. Paideia: a formação do homem grego. São Paulo: Martins Fontes, 2003.

KANT, Inmanuel. Crítica da faculdade do juízo. Rio de Janeiro: Forense, 1990.

LIMA, Márcio José Silveira. As máscaras de Dioniso: filosofia e tragédia em Nietzsche. Ijuí: Unijuí, 2006.

LÖWITH, Karl. Nietzsche: philosophie de l'éternel retour du même. Trad. Anne-Sophie Astroup. Paris: Calmann-Lévy, 1991.

MACHADO, Roberto. O nascimento do trágico: de Schiller a Nietzsche. Rio de Janeiro: Jorge Zahar, 2006.

MACHADO. Roberto. Nietzsche e a polêmica sobre o nascimento da tragédia. Rio de Janeiro: Jorge Zahar, 2005.

NIETZSCHE, Friedrich Wilhelm. A visão dionisíaca do mundo. São Paulo: Martins Fontes, 2005.

NIETZSCHE, Friedrich Wilhelm. Assim falou Zaratustra: um livro para todos e para ninguém. São Paulo: FCA, 1985.

NIETZSCHE, Friedrich Wilhelm. Crepúsculo dos ídolos. São Paulo: Companhia das Letras, 2006.

NIETZSCHE, Friedrich Wilhelm. Dernières lettres. Paris: Rivages, 1989.

NIETZSCHE, Friedrich Wilhelm. Ecce homo: como alguém se torna o que é. Porto São Paulo: Companhia das Letras, 1995.

NIETZSCHE, Friedrich Wilhelm. Fragmentos póstumos. Ed. espanhola dirigida por Diego Sanchez Meca. [S.1.]: Tecnos, 2010b. v. IV, 1885-1888.

NIETZSCHE, Friedrich Wilhelm. O nascimento da tragédia. São Paulo: Companhia de Bolso, 2008. 
OLIVEIRA, Ibraim Vitor de. Arché e Telos: niilismo filosófico e crise de linguagem em Fr. Nietzsche e M. Heidegger. Roma: Pontificia Università Gregoriana, 2004. (Tesi Gregoriana. Filosofia 21).

PINHEIRO, Paulo. Drama e fidelidade em Nietzsche. In: FEITOSA, Charles;

BARRENECHEA, Miguel Angel de; PINHEIRO, Paulo (Org.). A fidelidade à Terra: arte, natureza e política: assim falou Nietzsche IV. Rio de Janeiro: DP\&A, 2003.

ROHDE, Erwin. Resenha publicada no Norddeutsche Algemeine Zeitung de 26 de maio de 1872. In: MACHADO, Roberto (Org.). Nietzsche e a polêmica sobre O nascimento da tragédia. Rio de Janeiro: Jorge Zahar Editor, 2005.

SCHOPENHAUER, Arthur. Metafísica do belo. São Paulo: Editora Unesp, 2001.

SCHOPENHAUER, Arthur. O mundo como vontade e como representação, v. 3.

Disponível em: <www.filosofia.com.br/vi_relato.php?id=39>. Acesso em: 15 set. 2011.

SCHOPENHAUER, Arthur. O mundo como vontade e como representação. São Paulo: Editora Unesp, 2005. v. 1.

SILVA, Vagner. A tipologia nietzscheana. Dialogia, v. 7, n. 1, p. 103-112, 2008. Disponível em: 〈www.uninove.br/PDFs/Publicacoes/dialogia/dialogia_v7n1/dialogia_v7n1_4h08.pdf> acesso em: 20 maio 2012. 